\title{
COVID-19 Effects on Higher Education: A Case Study
}

\section{Dr. Boshra Karimi, Northern Kentucky University}

Dr. Boshra Karimi is an Assistant Professor of Construction Management at Northern Kentucky University. She received the Ph.D. degree in Civil and Environmental Engineering (Construction Management) from Oklahoma State University, the MSc degree in Industrial Engineering and Management from Sharif University of Technology, and the BSc degree in Mechanical Engineering from University of Tehran. She has over 10 years of experience in teaching and research. Prior to joining NKU as an Assistant Professor, she worked as a visiting instructor in the School of International Studies and Outreach and as a teaching associate in the School of Construction Management Technology at Oklahoma State University. She has also worked as an instructor at Ershad Damavand University. In addition, she has over 14 years of experience in industry. Her research interests include sustainable project management, sustainability assessment, sustainable technology implementation, supply chain management, decision-making modeling, and big data application in construction. Her research has been published in several peer reviewed journals and presented at international conferences. Dr. Karimi has received numerous awards and recognitions including "Summer Fellowship Award" in 2019 and 2020, "Robberson Summer Research and Creative Activity Fellowship" in 2017, "Calvin \& Marilyn Vogt Endowed Scholarship" in 2016, "Outstanding Teaching Performance Award" in 2014 \& 2015, and "Creativity, Innovation and Entrepreneurship (CIE) Scholarship" in 2014.

\section{Dr. Mahdi Yazdanpour, Northern Kentucky University}

Dr. Mahdi Yazdanpour is an Assistant Professor of Mechatronics Engineering Technology at Northern Kentucky University. He is also the advisor of the Norse Robotics Club (NRC) and IEEE student chapter at NKU. Dr. Yazdanpour received the PhD degree in Electrical Engineering from Oklahoma State University, the MSc degree in Industrial Engineering from Amirkabir University of Technology (Tehran Polytechnic), and the BSc degree in Computer Engineering from Qazvin Azad University. He has over 11 years of experience in manufacturing industry. He has worked as a Process Quality Manager, Planning \& Quality Systems Manager, Production Planning \& Control Manager, and Material Control Supervisor at MAPNA and NeyrePerse industrial groups. His research interests include Intelligent Mechatronic Systems, Medical Robotics, Companion Robots, Brain-Controlled Robots, Computer Vision, 3D Scene Reconstruction, and Machine Vision. His current research is focused on designing and implementation of the gesture and mind-controlled robotic systems. His research has been published in peer-reviewed journals and presented at international conferences. Dr. Yazdanpour has received numerous awards and recognitions including "The Best Paper Award in 15th IEEE Workshop on PBVS in conjunction with CVPR" in 2019, "CEAT Dean's Outstanding ECE Graduate Student Award" in 2018, "The FGSH Research Award" in 2017, "Creativity, Innovation, and Entrepreneurship (CIE) Scholarship" in 2017, "CEAT Outstanding Teaching Assistant Award" in 2016, and "Calvin \& Marilyn Vogt Endowed Scholarship Award" in 2016.

\section{Dr. Phil Lewis, Texas A\&M University}

Dr. Lewis is an Associate Professor and Associate Department Head in the Department of Construction Science as Texas A\&M University. He also serves as the Graduate Program coordinator for the Department. He teaches graduate and undergraduate courses in construction management. His primary research focus area is the economic, environmental, and energy impacts of construction. 


\title{
COVID-19 Effects on Engineering Technology and Construction Management Students: A Case Study
}

\begin{abstract}
The COVID-19 pandemic has dramatically affected higher education across the country. Many colleges and universities responded swiftly to this outbreak by moving to remote learning in order to cope with the pandemic. The responses varied in different education systems at national and international levels, but a commonality can be found between the most institutions worldwide: transitioning delivery mode from face-to-face teaching to remote learning approaches using online platforms. Although this new remote teaching format was different from classic online pedagogy in many cases, it was the beginning of a new era in higher education to establish or expand the necessary infrastructure for online education.

Unfortunately, many college students encountered some difficulties due to this fast transition in addition to facing personal challenges such as unexpected job loss, restricted social activities, and mental health conditions like anxiety, depression, etc. Studies show that psychological distress and symptoms of mental illness in college students have been dramatically increased due to social isolation result of campus closure since the pandemic started.

In this research, we conducted two surveys to evaluate how engineering technology and construction management students have been impacted by the outbreak at Northern Kentucky University. The intended outcome of our research is to prepare a better plan to mitigate the effects of pandemic on students' educational experience and performance. This study measures different aspects of college students' demands such as satisfaction with their classes, connectedness to the university, learning requirements, and technology resources. Furthermore, a Chi-Square test was deployed to compare these impacts on students in terms of gender and personality. The finding of these surveys demonstrate that the pandemic had greater mental impact on female students, however introverted and extroverted students have expressed similar experience. In addition, this research shows that all academic levels have been impacted by the pandemic to some extent.
\end{abstract}

\section{Introduction}

The Coronavirus (COVID-19) has substantially affected a variety of different sectors in our communities. One of the sectors that has been impacted by this pervasive pandemic is higher education. Higher education responses to the pandemic differed slightly in various countries around the world. A study revealed a timely map of higher education responses to the pandemic across 20 countries located in 6 different regions, including Africa, Eastern Mediterranean, Europe, South-East Asia, Western Pacific, and Region of the Americas. The responses varied from 
no reaction or continuing traditional teaching strategies respecting through social distancing protocols on campus, to rapid transition to fully online delivery [1].

However, something was definite and common in all responses worldwide: transitioning delivery mode from face-to-face to remote learning, which in many cases was different from the classic online pedagogy. This imperative transition was the beginning of a new era in higher education to establish or expand the essential infrastructure for online education. Inadequately resourced institutions and underprivileged learners have been hardest hit due to limited access to internet and technology requirements [2].

Our university, like many other universities across the U.S., extended the spring break by one week in order to prepare the required platforms for online teaching, and to assist instructors and staff to become ready for this prompt transition. In this research, we have investigated the impacts of COVID-19 outbreak on our students. The objective of this work is to study how different aspects of college students' lives affected by the outbreak. To achieve this goal, a survey has been conducted to evaluate the students' engagement and satisfaction while they experience new learning environment. Moreover, we included an additional survey to compare the impacts of the pandemic on different categories of students.

\section{Literature review}

Many faculty members lacked online teaching experience while most students suffered from lack of self-discipline and a suitable learning environment at home when the pandemic started. However, taking advantage of some instructional strategies can smooth this unprecedented transition. Preparing emergency plans for unexpected problems to cover large scale new platform users is the first essential step. Adopting modular teaching methods can assist students to concentrate on online learning. Adjusting teaching speed may improve the effectiveness of information delivery in remote learning. Modifying students' homework and assignments and using different methods can strengthen students' active learning outside of the class [3].

Some research proposed effective education responses to the pandemic. A report prepared by the Global Education Innovation Initiative at the Harvard Graduate School of Education, and the Organization for Economic Co-operation and Development (OECD) assessed the education needs and responses in 98 countries. This research provided a checklist to ensure that all hardware, software, and support systems are available and functional in place to mitigate the effect of the COVID-19 on the education system. It introduced some education silver lining to this crisis such as introducing new technologies, increase of students' autonomy to manage their learning, strengthened the parents' involvement, and strengthened public-private relationship [4].

A study carried out by the education think-tank the "Times Higher Education" in 2018 shows that $63 \%$ of participants predicted that the majority of prestigious universities will be offering their full 
courses online by 2030 . Interestingly, just $24 \%$ found online learning to be more attractive compared to face-to-face learning. The US Department of Education analysis on more than 1,000 learning studies revealed that students outperform while learning online compared to classroombased students over most subjects and demographics [5]. Incorporating medical and mental health services, improving hygiene practices, developing responsive curriculum, and teacher training for online delivery are other strategies to implement for readiness towards a successful online learning experience [6].

A survey conducted in China on Ghanaian students to investigate student satisfaction with online learning since online learning has not been well-developed in Ghana. The finding shows that lack of togetherness in a community, high cost of internet for students who live abroad, and different time zones are the main challenges that confront Ghanaian students. The students' average perceived effectiveness and credibility of the online education was 3.77 out of 5. Moreover, they scored the challenges associated with online learning 3.51 out of 5 [6].

Another study used a field experiment with 458 students from three different majors at Universidad Auto'noma de Madrid to examine the effects of the pandemic on students' performance. The results demonstrate that the COVID-19 confinement had a significant positive impact on students performance. Furthermore, the study reveals that students are taking advantage of adequate time management which can result in improving their performance [7]. However, college students experienced social isolation due to campus closure, which result in affecting their mental health. Studies show that psychological distress, symptoms of mental illness, and worsening quality of sleep were dramatically increased since the pandemic started. A study conducted on 400 students and staff in Italy shows that the pandemic had greater impact on students compared to staff. It shows that the impact of the outbreak was greater on female students compared to male [8]. Studies confirm that psychological cost of social activities restrictions due to COVID-19 pandemic was potentially high. Moreover, bedtime and wake up time were pushed back and people experience lower quality sleep while they spend more time in bed [9].

Some studies categorized the pandemic effects on universities worldwide. The first challenge was transitioning from face-to-face classes to online teaching which took a toll on some faculty who have not had any online teaching experience [10]. Lack of enough infrastructure and resources for online delivery along with difficulties in teaching practical courses such as music and art classes made this shift even more challenging [11].

International students are more vulnerable since international border closure restricts them to travel back to their home countries while a lot of campuses and dorms are closed. As a result, food, accommodation, and safety insecurity contribute to their concern about their families who are far from them [12]. Mental health support systems are essential to provide guidance to help students, staff, and faculty manage their stress while they are coping with the pandemic. Moreover, 
assignment and evaluation types must fit into online delivery while academic integrity is taken into account [13].

University graduates not only suffered from final part of their education, but also from poor market conditions. They likely accept lower paid jobs due to the economic recession. Studies show that graduates from high predicted earnings may compensate for it through firm earnings, however graduates from other programs may experience permanent earning losses [14].

Although the literature highlights some challenges that higher education faces due to the COVID19 pandemic, there are still plenty of issues that need to be addressed. This paper focuses on these issues and investigates the challenges students facing during these unprecedented times. The results compare the impacts of the COVID-19 crisis on college students in different academic grades. Furthermore, it examines if the mental burden of the pandemic has meaningful differences between male vs. female students and introverted vs. extroverted students.

\section{Methodology}

Northern Kentucky University gender makeup is $64 \%$ female and $46 \%$ male. With respect to race and ethnicity, the diversity includes 80\% white, 8\% African American, 4\% Hispanic/Latino, 3\% two or more races, and 5\% others. According to the Fall 2020 enrollment information, 72\% of students are undergraduate while $26 \%$ are graduate; $29 \%$ of our students are Pell grant recipients; $45 \%$ of undergraduate students are first-generation; $39 \%$ of the students are in Science, Technology, Engineering, and Mathematics plus Health (STEM+H) majors; and 27\% are Accelerated Online Learning (AOL) or in an online major.

New freshmen (non-AOL) enrollment dropped by 6.3\%, new transfers (non-AOL) by 3.5\%, and new graduate (non-AOL) by $12.4 \%$ in Fall 2020. Some reasons are aligned with demographic changes in Midwest, but other reasons need to be found and be addressed. The overall retention is $-15.3 \%$.

The COVID-19 coronavirus pandemic forced most colleges and universities to make budget cuts to close widening budget shortfalls. Our university experienced about $\$ 10 \mathrm{M}$ of revenue impact as the results of housing, parking, dining, online fee waiver, athletics, and other challenges. Therefore, the main risks the university is facing include: enrollment declines, auxiliary revenue impacts, and state appropriation cuts. The university had used a contingency budget planning approach last summer to alleviate some of the aforementioned challenges. It includes travel/meal/entertainment freeze, extend hiring freeze, non-recurring salary/furloughs, and reduce retirement contribution from $10 \%$ to $7.5 \%$ to offset the economic effects of the pandemic. 
As mentioned before, retention and enrollment persistence, and growth rate are key challenges that most universities face now and probably in the upcoming year. Every 1\% growth in enrollment equals over $\$ 1 \mathrm{M}$, and every $1 \%$ growth in persistence equals nearly $\$ 1.2 \mathrm{M}$ for our university. Hence, to assist the university in addressing the retention issue, the need to find the most vulnerable group/s and address their challenges is inevitable.

Active Minds surveyed 2,086 college students in April 2020 and found out that $63 \%$ of students have difficulty staying connected with others during the pandemic [15]. The results of the literature review show that students are missing togetherness, and keeping them connected with the university is one of the most challenging goals to achieve. This disengagement may yield low retention rates.

We conducted a survey in the College of Business (COB) in Fall 2020 to measure the Business and Construction Management students' engagement and satisfaction. The survey objectives were to measure how students' expectations have been met regarding COB classes, and to measure students' connectedness with the university and their classes during the Fall 2020 semester. The distribution of the respondents is presented in Table 1 . The questions, results, and analysis will be discussed in the next section.

Table 1. Distribution of COB Survey Respondents

\begin{tabular}{c|c|c|c|c|c}
\hline Academic Level & First-year & Second-year & Third-year & Fourth-year & Master \\
\hline Percentage & $17 \%$ & $17 \%$ & $26 \%$ & $29 \%$ & $11 \%$ \\
\hline
\end{tabular}

Another survey was developed to measure how Construction Management and Engineering Technology students particularly have been affected by the COVID-19. It measures different aspects of students' lives including job loss, mental health, technology demand, and learning requirements.

The questions in the surveys were designed to evaluate different impacts of the crisis on students. These questions have been validated by five academic experts, which confirms the reliability of them for this purpose.

Total respondents included 149 undergraduate students from Construction Management (CMGT) and Engineering Technology (EGT) programs in Spring and Fall 2020. The data collected yield a comparison to see how different academic levels and categories of students have been impacted by the pandemic to find the most vulnerable group/s. This analysis will assist the university and other institutions to develop a better strategic plan to mitigate these effects in the upcoming year as well as the post pandemic era. The distribution of the respondents is shown in Table 2. 
Table 2. Distribution of CMGT and EGT Survey Respondents

\begin{tabular}{c|c|c|c|c}
\hline Academic Level & First-year & Second-year & Third-year & Fourth-year \\
\hline Percentage & $25 \%$ & $28 \%$ & $30 \%$ & $17 \%$ \\
\hline
\end{tabular}

\section{Data analysis}

In this section, we have used Excel and SPSS software to analyze and interpret the collected data. We categorized them into nine different sub-sections.

\section{1- Expectation of classes}

Students were asked about their expectations of their classes in the first survey. The participants expressed their opinion in response to this question by selecting one of these options: met, exceeded, or failed to meet. About one third of students were not satisfied with the classes due to quick transition to online learning. Master's level students adapted best to their classes, and only $14 \%$ of graduate students were not satisfied with the college experience (Fig. 1).

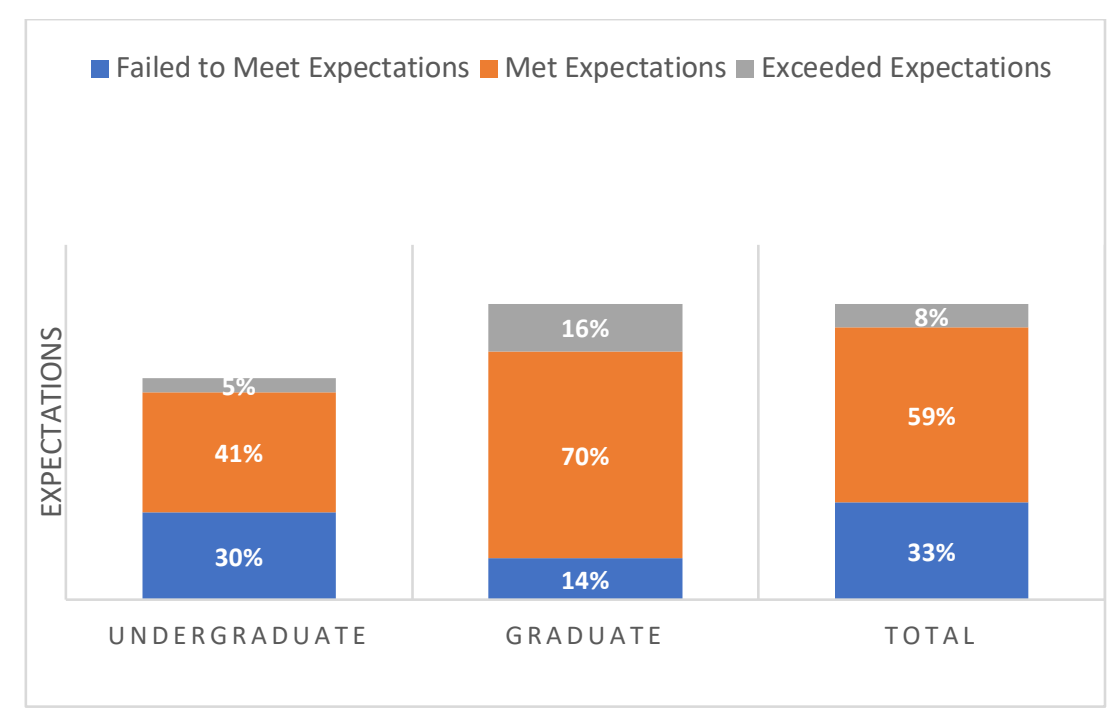

Figure 1. Comparison to Expectations among Graduate and Graduate Levels

First-year students adapted best to their classes. However, approximately 2 in 5 second-year, thirdyear, and fourth-year students believe their expectations have not been met (Fig. 2). 


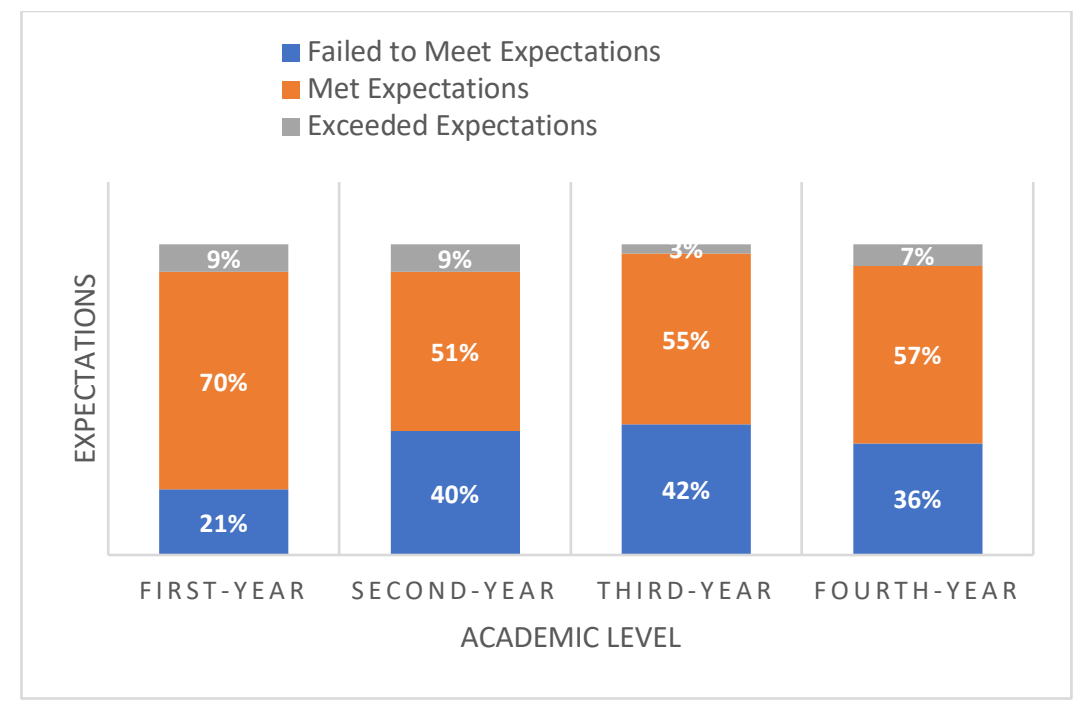

Figure 2. Comparison to Expectations among Different Undergraduate Levels

\section{2- Connection to the university and classes}

A previous study shows that students are suffering togetherness and connectedness during the pandemic [6]. Therefore, student connectedness to the university and classes versus this time last year have been questioned in our survey. Students had options from choosing "much more connected with the university and my Classes"; "slightly more connected with the university and my classes"; " about as connected with the university and my classes as I was in Fall 2019"; "slightly less connected with the university and my classes"; and "much less connected with the university and my classes".

The gap versus expectations may be explained by the disconnect these students feel to the university and their classes since third-year and fourth-year students feel less connected compared to second-year students. Across these grades, approximately three-fourths feel "much" or "slightly" less connected than they did during the Fall 2019 semester (Fig. 3). 


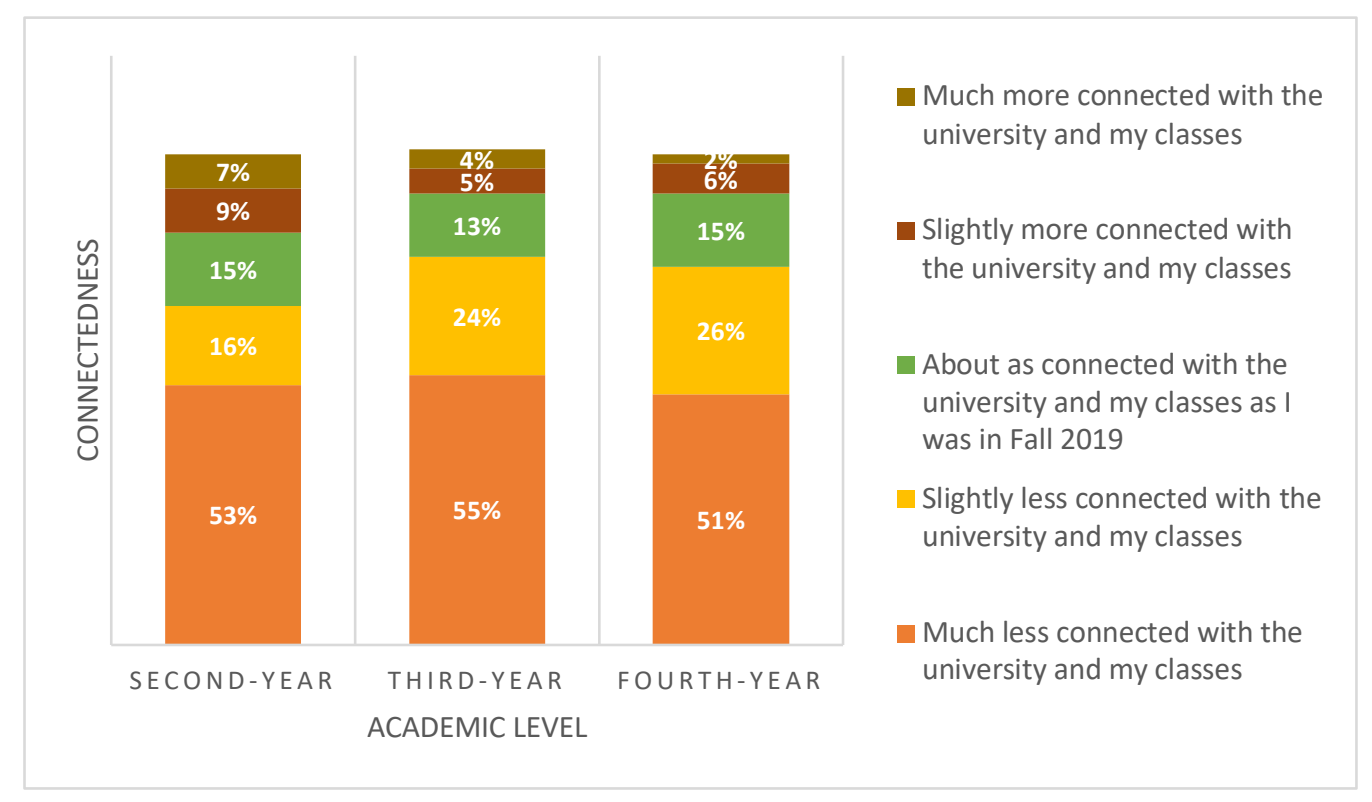

Figure 3. Connection to the University and Classes

3- Share of class types

It is pivotal to take "share of class types for different academic levels" into consideration to fully understand the gap in connectedness between different academic levels. Fig. 4 shows that in total, students report that $75 \%$ of their classes are completely online, a level that generally increases with the student's grade level. First-year students are getting the most face-to-face interaction. Secondyear students had the second highest percentage of face-to-face classes. Third-year and fourth-year students have the highest percentage of virtual classes, which makes them less connected to the college life.

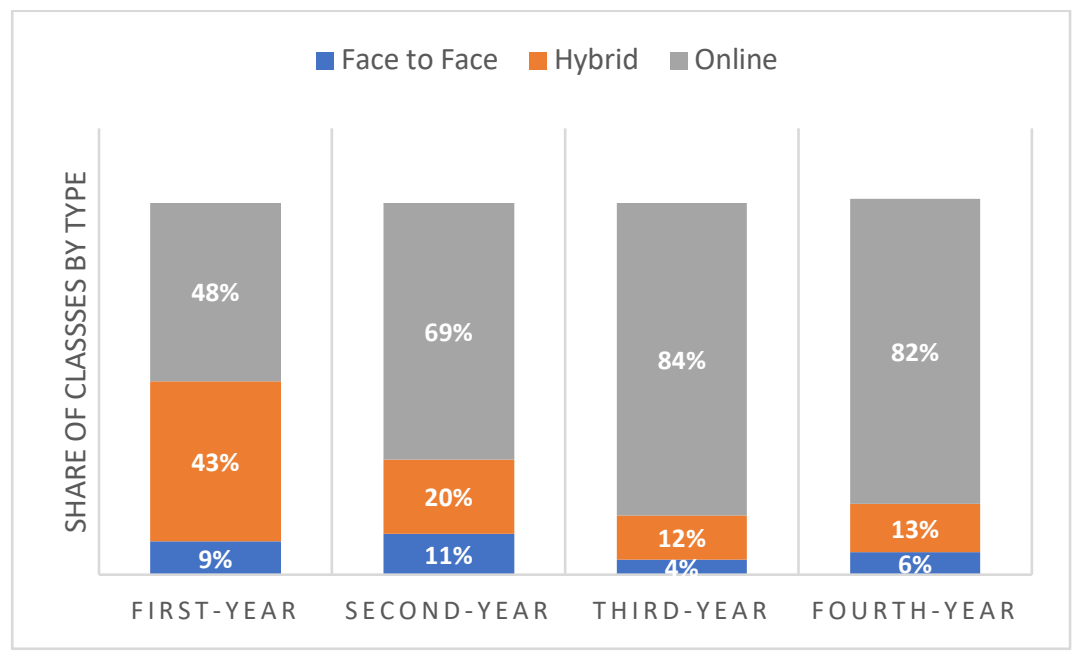

Figure 4. Share of Classes by Type 


\section{4- Worst outcome of COVID-19}

Online learning, social distancing, and unemployment are three major challenges students have been struggling with since the pandemic started. Therefore, students were asked to select the worst outcome of COVID-19. The results depict that different academic level students do not have the same perspectives. First-year and second-year students find online learning as the most challenging outcome of the pandemic, while third-year and fourth-year students perceive social distancing as the worst consequence of COVID-19 (Fig. 5). According to the survey, 75\% of students had taken online course before the pandemic started, which smoothed this prompt transition for third-and fourth-year students.

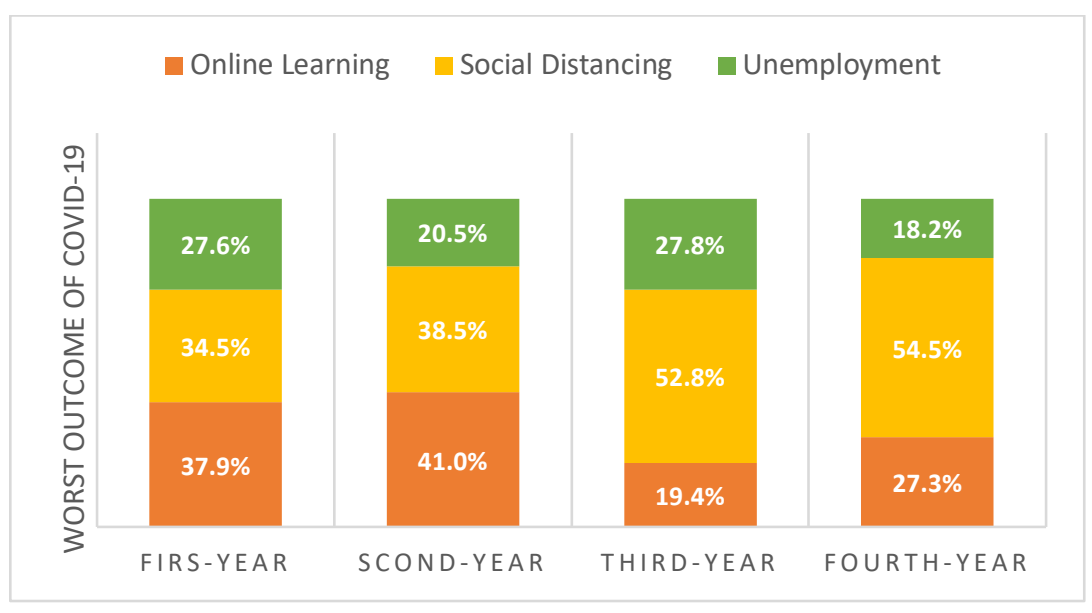

Figure 5. Worst Outcome of COVID-19

First-year and second-year students are new to the college. The results of the survey confirm that they perceive online learning as the worst outcome of the pandemic since it took away much needed connectedness and excitement at the beginning of their academic journey. Moreover, younger students may suffer more form lack of self-discipline, which makes it more difficult for them to maintain a routine with online learning.

This study reveals that $23 \%$ of students lost their jobs, and $10 \%$ of them lost their internship/coop opportunities due to the pandemic. Companies pushed back their internship/co-op positions or froze their hiring to mitigate the effects of COVID-19. Therefore, first-year and third-year students who were looking for either co-op or full-time positions have been affected harder compared to other academic level students by unemployment.

Social isolation has been perceived as the worst outcome of the pandemic by third-year and fourthyear students. They found it much more challenging to manage compared to the other outcomes. They have more experience with online learning and college lifestyle, however social insolation took a toll on them like many others. 


\section{5- Mental health}

A study shows that the outbreak had a greater impact on female students compared to male students [8]. Therefore, we wanted to examine if the pandemic had an appreciable impact on female students or not. Students were questioned if the new situation has affected their mental health. The results show that $82 \%$ of female students believed that the outbreak affected their mental health, while only $52 \%$ of male students found out the pandemic did so (Fig. 6).

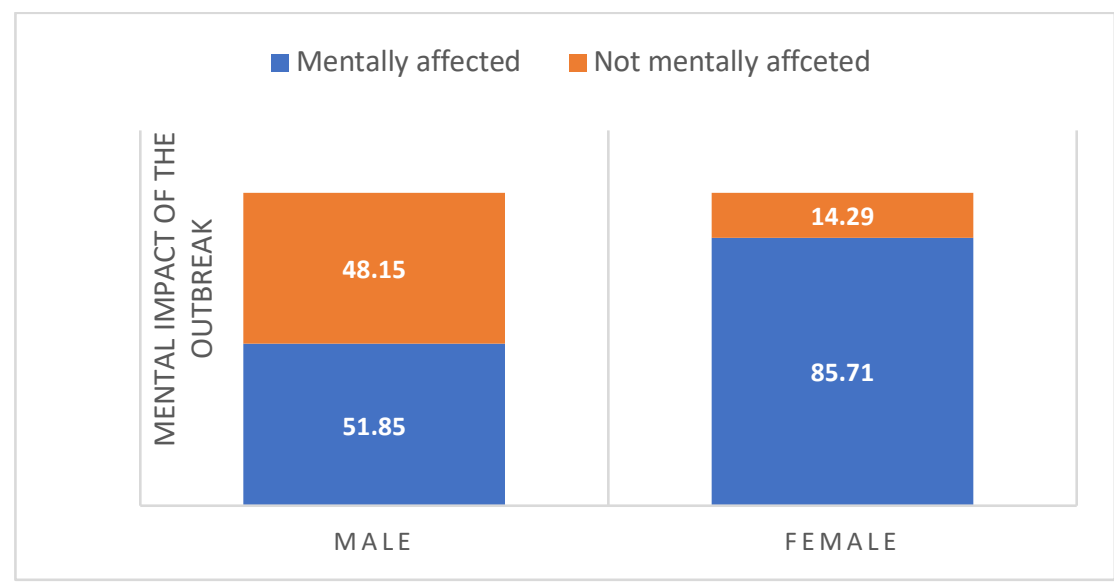

Figure 6. Mental Impact of the Outbreak on Different Genders

The Chi-Square test is a statistical procedure to examine the differences between categorical variables in the same population. In this research, a Chi-Square test was used to investigate if there is a statistically significant difference between how female and male students perceived the effect of the pandemic on their mental health. In addition, SPSS software was utilized to conduct the test and it showed that the p-value equals 0.015 , which is less than 0.05 significance threshold. It proves that there is a significant difference between male and female students' perception about how COVID-19 affected their mental health.

Students were questioned if they enjoy staying at home instead of going to school and work. The result shows that $21 \%$ of introverted students enjoy spending more time at home, whereas $14 \%$ of extroverted students find it more enjoyable. The Chi-Square test was conducted and the p-value equals 0.247 , which reveals that there is no significant difference between introverted and extroverted students regarding their enjoyment of staying at home. This result can be justified by $43.5 \%$ of extroverted students and $42.9 \%$ of introverted students, who believed that the outbreak affected their mental health. It can justify the aforementioned results and depicts that even though introverted students perceive staying at home as slightly more enjoyable, they were just as impacted as extroverted students by the pandemic. The summary of the Chi-Square test results is shown in Table 3. 
Table 3. Data Statistical Analysis Results

\begin{tabular}{c|c|c}
\hline Question & P-value & Statistical Difference \\
\hline Mental impact of pandemic on different genders & 0.015 & Significant \\
\hline Mental impact of pandemic on different personalities & 0.589 & Non-significant \\
\hline Different personalities' perception of staying at home & 0.247 & Non-significant \\
\hline
\end{tabular}

6- Students employment: change in hours

The majority of our students are employed, with the greatest percentage having increased their number of hours in comparison with last year. Students found an opportunity to work more, since most of the courses are being offered in online platforms. Additionally, some of them had to work more to make up for the salary cuts or job losses that happened to them or their family members. Table 4 shows the changes in hours by different academic levels. Third-year students increased their work hours by the greatest percentage and on average our students in COB are working $43 \%$ more compared to one year ago before the pandemic started.

Table 4. Change in Hours of Student Employment

\begin{tabular}{c|c|c|c|c|c|c}
\hline Academic level & First-year & Second-year & Third-year & Fourth-year & Master & Total \\
\hline Change in Hours & $+48 \%$ & $+43 \%$ & $+50 \%$ & $+37 \%$ & $+36 \%$ & $+43 \%$ \\
\hline
\end{tabular}

\section{7- Online delivery mode}

Students were questioned in our survey which delivery mode they prefer for their online courses. They chose among "pre-recorded lectures (asynchronous)"; "live lectures (synchronous)"; and "combination of synchronous and asynchronous lectures". The results reveal that under the new conditions, $50 \%$ of students preferred to have a combination of synchronous and asynchronous classes, 33\% liked asynchronous better, and 17\% of students found synchronous lectures more desirable (Fig. 7). The higher demand for asynchronous and combination delivery modes can be justified with increased working hours of students and the amount of flexibility they needed.

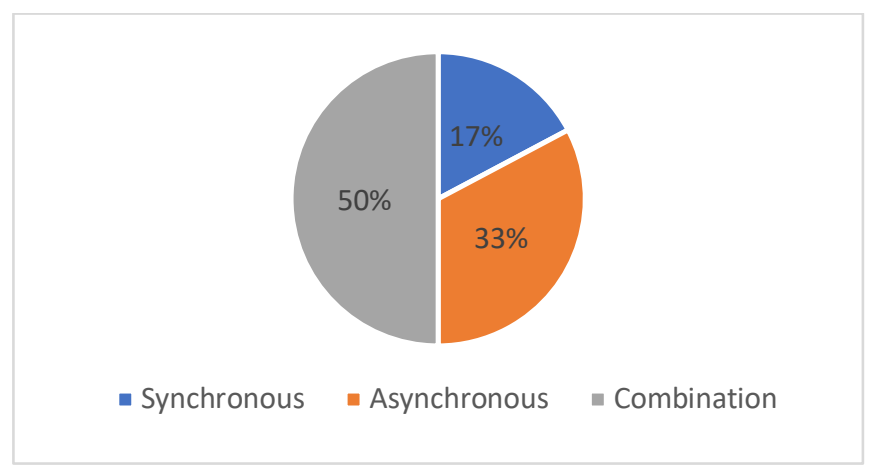

Figure 7. Share of Online Delivery Mode Preference 


\section{8- Other needs}

Our university created a Student Emergency Fund to support student success during the COVID19 Coronavirus outbreak. By November 20, 2020, the student emergency fund assisted 251 students among 813 total applications with 427 applications referred to the COVID-19 Coronavirus Aid, Relief, and Economic Security Act (CARES) fund. About 20\% of the CMGT and EGT students participated in these surveys applied for the Student Emergency Fund, and 50\% and $73 \%$ of them received the fund in Spring and Fall 2020, respectively.

In terms of required technologies, about $93 \%$ of them had reliable internet access and equipment for watching online video contents via Canvas or Zoom; 95\% for listening to the online audio contents; and $96 \%$ for reading and posting text. $73 \%$ of students had access to fast $\mathrm{Wi}-\mathrm{Fi} ; 89 \%$ to smartphone; and $97 \%$ to laptop or desktop computer. $98 \%$ of the educators did not have any concerns about accessing resources if the campus was closed, including basic needs (food, shelter, medical care), psychological care and counseling, a ride, or access to technology. However, $2 \%$ of students expressed their concerns regarding to using the university counselling service and the campus recreation center closure.

\section{9- Open-ended question}

An open-ended question was given to students to see how COVID-19 has affected students' lives. Table 5 shows these effects in three different categories: Academia, Health, and Monetary.

Table 5. COVID-19 Effects on Students' Lives

\begin{tabular}{l|l|l}
\hline \multicolumn{1}{c|}{ Academic Effects } & \multicolumn{1}{c}{ Health Effects } & \multicolumn{1}{c}{ Monetary Effects } \\
\hline - Difficult schedule & - Less support provided for & - Job loss \\
- Procrastination due to online & cancer patients & - More working hours \\
learning & - Having healthcare worker at & - Less co-op/internship \\
- Move out of dorms & - home & - Less income \\
- Distraction due to online & - Lack of emotional support & - Salary cut \\
learning & - system & \\
- Relocation & - Experiencing anxiety and & \\
- Lack of routine & - Menression & \\
- Switch to closer school to the & - Push back necessary surgery \\
home & & \\
- Lack of motivation & & \\
\hline
\end{tabular}

International students specifically expressed their concerns regarding to border shutdowns, which made them unable to visit their families during the pandemic. They were not only worried about their own health conditions, but also about their family members who were thousands of miles away from them. They could not reunite with their families during these unprecedented times, 
while domestic students could take advantage of moving back home to stay connected with their close ones and make online learning more cost effective.

Students were questioned if they found any benefits with staying at home. The majority of students found some silver linings and enjoyed at least part of their new lifestyles. The advantages of the global pandemic were categorized in three different groups based on students' feedback: Academia, Health, and Monetary as shown below (Table 6).

Table 6. Advantages of New Life Style Due to Pandemic

\begin{tabular}{l|l|l}
\hline \multicolumn{1}{c|}{ Academia } & \multicolumn{1}{c}{ Health } & \multicolumn{1}{c}{ Monetary } \\
\hline - Online delivery mode & - Having more free time & - Save money on gas and \\
- Flexibility of online classes & - Spend more quality time with & food \\
- More productivity & - family & \\
- Save time to not commute & - Less stress & \\
& - Self improvement & \\
& - More healthy food accessibility & \\
& - Rest more & \\
& - More comfortable & \\
\hline
\end{tabular}

The comparison between tables 5 and 6 depicts that students have different perception of the same situation under different conditions. While some found online learning more challenging due to lack of routine plans and motivation, others perceived it as an opportunity because of its flexibility and cost effectiveness. Other factors such as working hours, academic level, and gender need to be considered to fully understand these different perspectives.

\section{Discussion and conclusion}

The data and analysis presented in this study show how pandemic extensively affected the students' college life. It is crucial to take all the factors into consideration to fully understand and interpret the results. The survey results demonstrate that only $14 \%$ of graduate students were dissatisfied with their college experience during the pandemic while $30 \%$ of undergraduate students felt the university failed to meet their expectations. Due to this gap between graduate and undergraduate students' experience, only data related to undergraduate students have been analyzed for this study.

Second-year and third-year students were the least satisfied grades with their college experience whereas first-year and second-year students saw online learning the worst outcome of the pandemic compared to social distancing and unemployment. Third-year and fourth-year students felt less connected to the college and university compared to one year ago, while they got the least face-to-face interaction. These results reveal that all academic levels were impacted by the pandemic to some extent. Literature shows that students experience lack of togetherness and 
connectedness [6]. This research reveals that academic grades with higher percentage of virtual classes feel less connected to the university while students who are new to the college life suffer more from online learning and lack of routine life and self-discipline.

Previous study depicts that mental health of students have been impacted by the outbreak [8]. Although on average $50 \%$ of students believed that their mental health has been affected by the pandemic, statistical analysis of our survey data shows that the outbreak has a significantly greater impact on female students' mental health compared to males. However, the Chi-Square test did not find differences between introverted and extroverted students. This study shows that university utilized its resources effectively to meet the technology needs of students; however there is more room for improvement regarding to mental care and services. The university needs to offer more psychological supports for the most vulnerable groups.

Students found the combination of synchronous and asynchronous as the most advantageous online delivery mode during the pandemic. They found more flexibility when their working hours increased dramatically compared to one year ago while they can still experience some degree of connectedness to the university. Moreover, COVID-19 has altered the demand for classic online pedagogy. New formats of online learning has been established and widely utilized in academia since the pandemic started. Higher education established or expanded the required infrastructure for online education, which can be used in the post pandemic era to meet new demands and inaugurate more collaboration among universities nationally and internationally.

Retention and enrollment persistence and growth are the main challenges in higher education during and after the pandemic. It is crucial to find the most vulnerable groups to address these two challenges. Multiple studies show that the pandemic took a toll on international students and female students [12],[8]. This research shows that female and international students are among most vulnerable groups who have been impacted by the pandemic. Some forms of financial aids and mental health services need to be assigned to these groups specifically to support them in overcoming the hurdle of loneliness.

This study shows that third- and fourth-year students feel less connected to the university, therefore the optimum combination of online, hybrid, and face-to-face delivery modes can enhance the experience of college students. According to the results of this research, first-year and second-year students found online learning as the worst outcome of the pandemic compared to social distancing and unemployment. Hence, integrating self-discipline training or courses into curriculum especially for new college students will be a game changer during these unprecedented times. Imbedding more active learning elements, group projects and assignments, optional in-person labs and meetings, and breakout rooms activities to online courses besides sending weekly updates can stimulate students and mitigate the effect of social isolation. 


\section{References}

[1] J. Crawford, K. Butler-Henderson, J. Rudolph, B. Malkawi, M. Glowatz, R. Burton, P. A. Magni, S. Lam, “COVID-19: 20 countries' higher education intra-period digital pedagogy responses," Journal of Applied Learning \& Teaching, vol. 3, no. 1. April 2020.

[2] R. Zhong, “The coronavirus exposes education's digital divide,". The New York Times. March 2020. [Online]. Available: https://www.nytimes.com/2020/03/17/technology/chinaschools-coronavirus.html. [Accessed November 30, 2020].

[3] W. Bao, "COVID-19 and online teaching in higher education: A case study of Peking University," Wiley Online Library. April 2020. [Online]. Available: https://onlinelibrary.wiley.com/doi/full/10.1002/hbe2.191. [Accessed October 16, 2020].

[4] F. M. Reimers, A. Schleicher, "A framework to guide an education response to the COVID-19 Pandemic of 2020, "Learning portal: planning education for improved learning outcomes. 2020. [Online]. Available: https://learningportal.iiep.unesco.org/en/library/a-frameworkto-guide-an-education-response-to-the-covid-19-pandemic-of-2020

[5] J. Demuyakor, " Coronavirus (COVID-19) and Online Learning in Higher Institutions of Education: A Survey of the Perceptions of Ghanaian International Students in China," Online Journal of Communication and Media Technologies. 10(3), e202018. May 2020. [Online]. Available: https://doi.org/10.29333/ojcmt/8286. [Accessed October 16, 2020].

[6] C. M. Toquero, "Challenges and Opportunities for Higher Education amid the COVID-19 Pandemic: The Philippine Context," Pedagogical Research, 5(4). 2020.

[7] T. Gonzalez, M. A. de a Rubia, K. P. Hincz, M. Comas-Lopez, Laia Subirats, Santi Fort, G. M. Sacha, "Influence of COVID-19 confinement on students' performance in higher education, " Plos One, October 2020. [Online]. Available: https://journals.plos.org/plosone/article?id=10.1371/journal.pone.0239490. [Accessed October 14, 2020].

[8] S. Marelli, A. Castelnuovo, A. Somma, V. Castronovo, S. Mombelli, D. Bottoni, C. Leitner, A. Fossati, L. Ferini-Strambi, "Impact of COVID-19 lockdown on sleep quality in university students and administration staff," Journal of Neurology. July 2020.

[9] N. Cellini, N. Canale, G. Mioni, S. Costa, "Changes in sleep pattern, sense of time and digital media use during COVID-19 lockdown in Italy," Journal of Sleep Research. May 2020. [Online]. Available: https ://doi.org/10.1111/jsr.13052. [Accessed October 14, 2020]. 
[10] M. Lim, "Educating despite the COVID-19 outbreak: lessons from Singapore," The Word University Ranking Webiste. 2020. [Online]. Available: https://www.timeshighereducation.com/blog/educating-despite-covid-19-outbreaklessons-singapore. [Accessed December 24, 2020].

[11] E. Dill, K. Fischer,B. McMurtrie, and B. Supiano, "As coronavirus spreads, the decision to move classes online is the first. What comes next?" The Chronicle of Higher Education. March 6, 2020. [Online]. Available: https://www.chronicle.com/article/As-CoronavirusSpreads-the/248200. [Accessed December 24, 2020].

[12] Y. Zhai, X. Du, "Mental health care for international Chinese students affected by the COVID-19 outbreak, “ Lancet Psychiatry. vol. 7, no. 4.31. Mar 2020.

[13] P. Sahu, "Closure of Universities Due to Coronavirus Disease 2019 (COVID-19): Impact on Education and Mental Health of Students and Academic Staff," PubMed Central. vol. 12, no. 4. April 2020.

[14] S. Burgess, H. H. Sievertsen, " Schools, skills, and learning: The impact of COVID-19 on education," VoxEU. April 2020. [Online]. Available: https://voxeu.org/article/impactcovid-19-education. [Accessed December 24, 2020].

[15] "The impact of COVID-19 on student mental health," Active Minds. April 2020 survey data . [Online]. Available: https://www.activeminds.org/studentsurvey/. [Accessed January 26, 2021]. 